\title{
Predictors of Exclusive Breastfeeding Duration among Mothers Attending Immunization Clinic in a Tertiary Health Facility in Enugu, Nigeria
}

\author{
Christopher Bismarck Eke', Vina Okafor'2, Beckie N. Tagbo ${ }^{3}$, Nnamdi Benson Onyire ${ }^{4}$, \\ Francis Ikechukwu Ukekwes, Uzoamaka Vivian Muoneke ${ }^{{ }^{*}}$ \\ ${ }^{1}$ Department of Paediatrics, College of Medicine, University of Nigeria/University of Nigeria Teaching Hospital, Enugu, Nigeria \\ ${ }^{2}$ Institute of Maternal and Child Health, University of Nigeria Teaching Hospital, Enugu, Nigeria \\ ${ }^{3}$ Institute of Child Health/Department of Paediatrics, University of Nigeria Teaching Hospital, Enugu, Nigeria \\ ${ }^{4}$ Department of Paediatrics, Ebonyi State University/Federal Teaching Hospital, Abakaliki, Ebonyi State, Nigeria \\ ${ }^{5}$ Department of Morbid Anatomy, College of Medicine, University of Nigeria/University of Nigeria Teaching Hospital, Enugu, Nigeria \\ Email: christopher.eke@unn.edu.ng, ejivina@yahoo.com,tagbobeckie@gmail.com,nnamdionyire@yahoo.com, \\ drikukekwe@hotmail.com, *vizym@yahoo.com, ${ }^{*}$ uzoamakamuoneke@gmail.com
}

How to cite this paper: Eke, C.B., Okafor, V., Tagbo, B.N., Onyire, N.B., Ukekwe, F.I. and Muoneke, U.V. (2019) Predictors of Exclusive Breastfeeding Duration among Mothers Attending Immunization Clinic in a Tertiary Health Facility in Enugu, Nigeria. Open Journal of Pediatrics, 9, 62-74. https://doi.org/10.4236/ojped.2019.91007

Received: February 1, 2019

Accepted: March 15, 2019

Published: March 18, 2019

Copyright (c) 2019 by author(s) and Scientific Research Publishing Inc. This work is licensed under the Creative Commons Attribution International License (CC BY 4.0).

http://creativecommons.org/licenses/by/4.0/

\begin{abstract}
Background: Breastfeeding is cost effective means towards the realization of some key United Nations Sustainable Development Goals by the year 2030 particularly in resource limited settings. The objectives of the study were to evaluate the predictors of exclusive breastfeeding duration among mother and child pairs utilizing a tertiary immunization clinic facility. Methods: This was a cross-sectional descriptive study. Respondents were mother-and-child pairs who were recruited consecutively. Relevant maternal and child characteristics were collected using a semi-structured questionnaire. Data were analyzed using Statistical Package for Social Sciences version 20.0 ( $\mathrm{p}<0.05)$. Results: Four hundred and twenty seven mother-child pairs were studied. Majority of the mothers have at least secondary education, 383 (80.7\%). 407 (95.3\%) of the mothers fully understood the actual meaning of EBF. 189 (42.7\%) reported practicing EBF in their index child for six months. Maternal perception of insufficient milk production, 52/99 (52.5\%) was the most common reason for practicing EBF for $<6$ months among respondents. Maternal education and occupation and gender of the child were significantly associated with completion of EBF for 6 months among respondents. Conclusion: EBF duration in the current study is low and is significantly associated with maternal education, maternal occupation and gender of the child. Improving girl child education, complementing baby friendly hospital initiative with baby friendly community initiative should be adopted to improve EBF duration in our setting.
\end{abstract}




\section{Keywords}

Predictors of Exclusive Breast Feeding Duration, Mother-Child Pair

\section{Introduction}

The World Health Organization (WHO) and United Nations Children's Fund (UNICEF) global recommendations on breastfeeding are hinged on exclusive breastfeeding for the first six months and continued breastfeeding for two years or more in children [1].

Optimal breastfeeding up to two years following the AMLET guidelines has the greatest potential/impact in child survival of all preventative interventions with the likelihood to prevent well over 800,000 deaths (13 percent of all deaths) in children under five in developing countries [1] [2] [3].

Sub-optimal breastfeeding within the first six months of life results in 1.4 million deaths and ten percent of diseases in children under five years of age. Early initiation and sustenance of exclusive breastfeeding (EBF) would therefore help to fast track the realization of reduced child mortality indices [2] [3].

Early EBF enables children to survive generally, supporting brain development, improving cognitive performance and has been associated with higher educational achievements at age five [1].

Breast milk essentially contains all the nutrients, including vitamins and minerals an infant requires for optimal growth and development within the first six months of life. It also contains maternal antibodies that help to protect the child from several infections in infancy as well as lowering the possibility of development of chronic disorders later in life particularly obesity and its complications of cardio-metabolic syndrome; and asthma [1] [4] [5]. Breastfeeding creates a special bonding between the mother and the nursing infant [1].

Regarding maternal health, the benefits of EBF cannot be over-emphasized as early initiation and sustenance of EBF contributes to the reduction of the risk of post-partum haemorrhage and serves as a means of natural birth control as well as post-partum depression [5], while in the long term reduces the likelihood of development of some maternal gynaecological malignancies including breast, uterine and ovarian carcinomas [1] [6] [7].

Generally, all nursing mothers can exclusively breastfeed given the right support, counselling and encouragement to enable them to cope with the challenges of successful EBF in their young infants. Several maternal, child, cultural, environmental and commercial pressures currently mitigate against the sustenance of EBF among mothers particularly aggressive marketing and promotion of formula (breast milk substitutes) by the industries [1].

Globally over 830 million mothers are working and a significant number return to work soon after delivery requiring that there should be a need for supportive maternal policies and legislation to cover longer periods of paid mater- 
nity leave and breastfeeding breaks to enable them to continue breastfeeding [1]

Many mothers also work in the informal, seasonal, or part-time sectors and face even greater challenges to EBF. Adequate family, community as well as institutional support should be available to such mothers to enable them cope with the demands of sustaining EBF in their young children. Globally, there have been rising breastfeeding rates especially in the past decade through the realization of the Millennium Development Goals [8] [9].

However, only 39 percent of children less than 6 months of age in the developing countries are exclusively breastfed [1] [8]. In Nigeria according to the latest national demographic and health survey (NDHS) of 2013, only 17 percent of children under six months of age are exclusively breastfed while about 10 percent are exclusively breastfed up to 4 - 5 months of age. Further $35 \%$ continue breastfeeding up to age two years as recommended by WHO and UNICEF [10].

Studies exist both locally and elsewhere [11]-[19]; in this subject however, gaps exist regarding the actual determinants of EBF in contemporary Nigeria with a rising number of working mothers in an economy currently in transition.

Hence the objectives of the study were to evaluate the determinants of exclusive breastfeeding duration among mother-and-child pairs utilizing a tertiary immunization clinic facility in Enugu, Nigeria.

\section{Methods}

This was a cross-sectional descriptive study conducted at the Immunization Clinic of the Institute of Child Health (ICH), of the University of Nigeria Teaching Hospital (UNTH), Enugu in 2016.

Ethical approval was obtained from the Human Research Ethics committee of the University of Nigeria prior to the commencement of the study.

Study subjects were all eligible mothers with their respective child pairs who were attending the immunization clinic of the Institute of Child Health in the hospital during the study period and were consecutively recruited upon the mother's informed written consent.

The inclusion criteria for the study were all mother-child pairs aged 6 months to 23 months attending the Immunization Clinic during the study period.

Mother-child pairs were excluded from the study if mother declined consent, child less than 6 months of age, or child not accompanied by mother to the immunization clinic.

Informed written consent was obtained from all eligible mothers. Thereafter, a pretested interviewer administered semi-structured questionnaire was used to obtain relevant information from all the consented respondents.

\subsection{Study Participation and Data Collection}

Relevant information included in the study protocol included-maternal socio-demographic characteristics (age, marital status, highest level of educational attainment, current employment); paternal socio-demographic variables (age, 
educational attainment level, present occupation); maternal and child biomedical variables (parity, antenatal visits, mode of delivery, index child's gender as well as gestational age at birth and birth weight), household variables (number of children in the family) and duration of exclusive breastfeeding as well as length of total breastfeeding. The social class of each child was determined subsequently using the occupation as well as highest educational attainment of both mother and father using the method proposed by Oyedeji [20].

In the study, exclusive breast feeding (EBF) was defined as the infant/child who received only breastmilk from the mother either directly from the breast or expressed and no other liquids or solids with the exception of drops or syrups containing vitamins, mineral supplements or medicines [21].

Information obtained from the mother were mainly by recall.

\subsection{Data Analysis}

Data was analysed using Statistical Package for Social Sciences (SPSS) windows programme (SPSS Inc., Chicago, IL, USA) version 20.0, and results presented in percentages. Chi-square was used to compare proportions. The dependent variable is EBF. Univariate associations between various factors and EBF adjusting for the child's age were identified. Further Statistical analysis was done to determine the independent association of various factors to EBF. The level of Statistical Significance was set at $\mathrm{p}<0.05$.

\section{Results}

A total of four hundred and twenty-seven mother-child pairs were recruited and interviewed. Majority of the mothers 230 (53.9\%) were between the 20 to 29 age bracket.

Two hundred and twenty eight (53.4\%) and 199 (46.6\%) of the studied children were males and females respectively giving a male to female ratio of 1.09 to 1.0 .

Majority of the mothers, $383(80.7 \%)$ had at least secondary education while 301 (70.5\%) had some sort of employment as shown in Table 1.

Four hundred and twenty-three (99.1\%) of the mothers have heard of exclusive breastfeeding while majority, $334(78.2 \%)$ reported that they got knowledge of exclusive breastfeeding from previous antenatal or immunization clinic. 407 (95.3\%) of the mothers fully understood the actual meaning of exclusive breastfeeding (EBF), while 288 (67.4\%) reported practicing EBF in the index child pair as shown in Table 2. Correct practicing of EBF for a total of six months duration was reported by 189 (42.7\%) of the mothers.

However, among mothers who breastfed their babies for less than six months, the reasons advanced included; maternal perception of production of insufficient breastmilk $52(52.5 \%)$ baby not adding adequate weight 10 (19.2\%), baby needs water to drink $18(18.2 \%)$ and pressure of work, 10 (10.1\%). See Table 2. 
Table 1. Socio demographic characteristics of mother and child pair subjects.

\begin{tabular}{|c|c|c|}
\hline Characteristics & Frequency $(n=427)$ & Percent (\%) \\
\hline \multicolumn{3}{|l|}{ Age of Mother: } \\
\hline $20-<30$ & 230 & 53.9 \\
\hline $30-<40$ & 186 & 43.6 \\
\hline$\geq 40$ & 11 & 2.6 \\
\hline \multicolumn{3}{|l|}{ Age of Children: } \\
\hline$<6$ months & 03 & 0.7 \\
\hline $6-<12$ months & 320 & 74.9 \\
\hline$\geq 12$ months & 104 & 24.4 \\
\hline \multicolumn{3}{|l|}{ Sex of Children: } \\
\hline Male & 228 & 53.4 \\
\hline Female & 199 & 46.6 \\
\hline \multicolumn{3}{|l|}{ Birth Order of Children: } \\
\hline $1-3$ & 318 & 74.5 \\
\hline$\geq 4$ & 109 & 25.5 \\
\hline \multicolumn{3}{|l|}{ Maternal Education: } \\
\hline No Formal Education & 2 & 0.5 \\
\hline Primary & 42 & 9.8 \\
\hline Secondary & 173 & 40.5 \\
\hline Tertiary & 210 & 49.2 \\
\hline \multicolumn{3}{|l|}{ Maternal Occupation: } \\
\hline Unemployed & 126 & 29.5 \\
\hline Self employed & 177 & 41.5 \\
\hline Privately employ & 45 & 10.5 \\
\hline Government Employed & 79 & 18.5 \\
\hline
\end{tabular}

Among children who were not exclusively breastfed, other foods they were given included: breastmilk and formula, 89 (64.0\%), infant formula alone 9 (6.5\%), breastmilk plus locally sourced complementary foods 17 (12.2\%), and breastmilk plus commercially packaged complementary foods 4 (2.9\%), and breastmilk with formula and locally prepared complementary feeds in 16 (11.5\%) respectively as shown in Table 2.

The relationship of practice of EBF with maternal and child characteristics were statistically significant for gender of the child $(p=0.041)$, maternal education $(\mathrm{p}=0.016)$, and maternal occupation $(\mathrm{p}=0.000)$ as shown in Table 3 .

On further statistical analysis using bivariate analysis only maternal education $(\mathrm{p}=0.002)$ was statistically significant in association to the correct duration of exclusive breastfeeding as shown in Table 4.

\section{Discussion}

In the current study majority of the mothers have heard of excusive breastfeeding 
Table 2. Exclusive breastfeeding practice by mothers.

\begin{tabular}{|c|c|c|}
\hline Characteristics & Frequency $(n=427)$ & Percent (\%) \\
\hline \multicolumn{3}{|l|}{ Heard of EBF: } \\
\hline Yes & 423 & 99.1 \\
\hline No & 04 & 0.9 \\
\hline \multicolumn{3}{|l|}{ Source of Knowledge of EBF: } \\
\hline Family/Friends & 42 & 9.8 \\
\hline ANC/Immunization Clinics & 334 & 78.2 \\
\hline Media & 20 & 4.7 \\
\hline All of the above & 31 & 7.3 \\
\hline \multicolumn{3}{|l|}{ Understands meaning of EBF: } \\
\hline BM alone & 407 & 95.3 \\
\hline $\mathrm{BM}+$ water & 13 & 3.0 \\
\hline $\mathrm{BM}+$ formula & 7 & 1.6 \\
\hline \multicolumn{3}{|l|}{ Practice of EBF in the Index Child: } \\
\hline Yes & 288 & 67.4 \\
\hline No & 139 & 32.5 \\
\hline \multicolumn{3}{|l|}{ Duration of EBF Practiced $(n=288)$ : } \\
\hline 6 months & 189 & 44.2 \\
\hline 4 - 5 months & 52 & 12.2 \\
\hline $2-3$ months & 47 & 11.0 \\
\hline \multicolumn{3}{|l|}{ Reasons for EBF < 6 months $(n=99)$ : } \\
\hline Insufficient breastmilk (BM) & 52 & 52.5 \\
\hline Baby not adding adequate weight & 19 & 4.4 \\
\hline Baby needs water & 18 & 4.2 \\
\hline Pressure of work & 10 & 2.3 \\
\hline \multicolumn{3}{|l|}{ Other foods child was } \\
\hline give before 6 months $(\mathrm{n}=139)$ : & 89 & 20.8 \\
\hline Formula + Breast Milk Infant formula & 9 & 2.1 \\
\hline Local CFs + BM & 17 & 4.0 \\
\hline Prepackage CFs + BM & 4 & 0.9 \\
\hline Family Diet/Ration + BM & 2 & 0.5 \\
\hline Formula $+\mathrm{BM}+\mathrm{LCF}$ & 16 & 3.7 \\
\hline Formula + BM + PPCF & 2 & 0.5 \\
\hline \multicolumn{3}{|l|}{ Facility for Creche: } \\
\hline Yes & 26 & 6.1 \\
\hline No & 401 & 93.9 \\
\hline
\end{tabular}

and also understood its actual meaning as well as its advantages. This has been corroborated by other workers, working independently [21] [22].

Less than half of the mothers 189 (42.7\%) in the current study practiced EBF up to the infant age six months. This rate is slightly high compared to previous 
Table 3. Relationship of practice of EBF with maternal and child characteristics.

\begin{tabular}{|c|c|c|c|c|c|}
\hline \multirow[t]{2}{*}{ Characteristics } & \multicolumn{2}{|c|}{$\begin{array}{c}\text { Mothers/Caregivers } \\
\text { Responses }\end{array}$} & \multirow{2}{*}{$\begin{array}{c}\text { Total } \\
(\mathrm{N}=427)\end{array}$} & \multirow[t]{2}{*}{$\mathrm{X}^{2}$} & \multirow[t]{2}{*}{ P-value } \\
\hline & Yes (n\%) & No (n\%) & & & \\
\hline Maternal Age (years): & & & & 2.257 & 0.324 \\
\hline $20-<30$ & $153(66.5)$ & $77(33.5)$ & $230(100.0)$ & & \\
\hline $30-<40$ & $133(71.5)$ & $53(28.5)$ & $186(100)$ & & \\
\hline$\geq 40$ & $6(54.5)$ & $5(45.5)$ & $11(100.0)$ & & \\
\hline Birth Order: & & & & 2.545 & 0.457 \\
\hline First & $55(61.8)$ & $34(38.2)$ & $89(100.0)$ & & \\
\hline Second & $94(70.7)$ & $39(29.3)$ & $133(100.0)$ & & \\
\hline Third & $67(69.8)$ & $29(30.2)$ & $96(100.0)$ & & \\
\hline$\geq$ Fourth & $71(65.1)$ & $38(34.9)$ & $109(100.0)$ & & \\
\hline Sex of Baby: & & & $223(100.0)$ & 3.406 & $0.041^{*}$ \\
\hline Male & $161(72.2)$ & $62(27.8)$ & & & \\
\hline Female & $127(62.3)$ & $77(37.7)$ & $204(100.0)$ & & \\
\hline \multicolumn{6}{|l|}{$\begin{array}{l}\text { Maternal } \\
\text { Education: }\end{array}$} \\
\hline No formal Education & $1(50.0)$ & $1(50.0)$ & $2(100.0)$ & 10.393 & $0.016^{*}$ \\
\hline Primary & $24(57.1)$ & $18(42.9)$ & $42(100.0)$ & & \\
\hline Secondary & $107(61.8)$ & $66(38.2)$ & $173(100.00)$ & & \\
\hline Tertiary & $156(74.3)$ & $54(25.7)$ & $210(100.0)$ & & \\
\hline \multicolumn{6}{|l|}{$\begin{array}{l}\text { Maternal } \\
\text { Occupation: }\end{array}$} \\
\hline Unemployed & $87(69.0)$ & $39(31.0)$ & $126(100.0)$ & 18.055 & $0.001^{*}$ \\
\hline Self employed & $112(63.3)$ & $65(36.7)$ & $177(100.0)$ & & \\
\hline Private employed & $23(51.1)$ & $22(48.9)$ & $45(100.0)$ & & \\
\hline Government employed & $66(83.5)$ & $13(16.5)$ & $79(100.0)$ & & \\
\hline \multicolumn{6}{|l|}{$\begin{array}{c}\text { Rate of Understanding } \\
\text { of EBF: }\end{array}$} \\
\hline Yes & $227(68.6)$ & $127(31.4)$ & $404(100.0)$ & 0.024 & 0.537 \\
\hline No & $10(66.7)$ & $5(33.3)$ & $15(100.0)$ & & \\
\hline \multicolumn{6}{|l|}{ Facility for Creche: } \\
\hline Yes & $48(75.0)$ & $16(25.0)$ & $64(100.0)$ & 1.690 & 0.127 \\
\hline No & $99(66.0)$ & $51(34.0)$ & $150(100.00)$ & & \\
\hline
\end{tabular}

${ }^{\star}$ EBF: Exclusive breastfeeding as defined by the World health organization is feeding of the infant only breast milk and no other liquids or solids except for drops or syrups consisting of vitamins, mineral supplements, or medicines. [45]

reports from Nigeria [22] [23] and the Nigerian National Demographics and Health Survey (NDHS) of 2013 [10], and among breastfeeding mothers in the United States of America [24] [25]. However, the finding in the present study is much lower than the findings in a similar study in Ethiopia in East Africa [26]. 
Table 4. Bivariate regression of practice of exclusive breastfeeding and maternal and child characteristics.

\begin{tabular}{ccc}
\hline Characteristics & Pearson Correlation $(\mathrm{N}=427)$ & P-value \\
\hline Age of Mother & -0.028 & 0.562 \\
Sex of Child & -0.057 & 0.239 \\
Birth Order & -0.055 & 0.261 \\
Maternal Education & -0.152 & $0.002^{\star}$ \\
Maternal Occupation & -0.072 & 0.139 \\
Facility for Creche & 0.089 & 0.195 \\
Maternal Understanding of Exclusive & 0.008 & 0.877 \\
\hline
\end{tabular}

${ }^{*}$ Exclusive breastfeeding as defined by the World health organization is feeding of the infant only breastmilk and no other liquids or solids except for drops or syrups consisting of vitamins, mineral supplements, or medicines [45].

Though EBF is perceived as the preferred feeding option for all infants globally, EBF practice among the respondents in the current study showed more male preponderance. Culturally in our setting the males are raised to inherit and carry the family names and some families may give them preferential treatment including exclusive breastfeeding for up to 6 month in order to make them stronger and more intelligent children. However this perception is fast changing following education [27] [28].

In the current study majority of the mothers had at least secondary education. Maternal education is associated with adequate knowledge of child care practices including exclusive breastfeeding. Maternal education is one of the major determinants of the adequate EBF. Similar to this finding in the present study, other researchers on EBF rate and duration have reported a positive association between maternal education and knowledge and practice of EBF [20] [27] [29]. However Dubois and co-worker [30] reported that maternal education has no significant influence on EBF rate in a longitudinal study on child development in Quebec, Canada in North America. The possible reason for this variation could be that Canada is a highly developed economy with higher adult literacy rate and functional health system making the importance of maternal education to be affected by other co-founders.

Maternal occupation similarly influenced practice of exclusive breastfeeding among mothers in the current study. Mothers who were unemployed/self-employed tended to breastfeed their babies more and completed EBF up to 6 months in their infants compared to those working either in private or public sector [31] [32]. It has been reported that returning to work soon after delivery may influence women's decision to discontinue exclusive breastfeeding before 6 months. Also in countries that have federal legislation which supports the rights of working mothers to breastfeed their babies on the job tend to have higher rates of mothers who exclusive breastfed their babies up to 6 months [33] [34] [35].

Nigeria recently introduced four months fully paid maternity leave for all 
nursing mothers working in the public sector. However, this legislation does not apply for the privately employed as different organizations have their own policies with regards to maternity leave [36]. UNICEF in its 2015 Breastfeeding week theme titled "to empower women to combine work with breastfeeding and raising their children in its bid to further promote the practice of EBF [1] [37]. Hence measures should be put in place by all signatory member nations of the World Health Assembly particularly among the low-income countries including Nigeria to create enabling legislation to protect and support breastfeeding mothers who are engaged in all manner of work whether public or private, formal or informal sectors.

Among mothers who practiced EBF for less than six months several determinant factors were advanced including maternal production of insufficient breastmilk, baby not gaining adequate weight, baby needs to drink water and maternal pressure of work.

Some workers observed that ninety-five percent of infants less than 3 months received breastmilk and water owing to maternal cultural beliefs [38]; that the breastmilk does not have sufficient water content needed by the baby for proper growth and development while others felt that their infants were hungry after breastfeeding, making them to introduce other feeds to satisfy their cues and also make them gain more weight [39].

Also, some mothers have linked the satisfaction of their infant following breastfeeding to their quantity of milk production. If the infant cries soon after feeding implications are that mother is not producing enough breastmilk-and hence the need to "switch" either to formula or practice mixed feeding and/or commence complementary feeding [40] [41] [42].

All these erroneous impressions about EBF could be addressed by having a motivated baby friendly hospital initiative (BFHI), [43] complemented by baby friendly community initiative (BFCI) [44] to provide adequate support to breastfeeding mothers both in hospital as well as in their respective communities thereby improving EBF rate and duration further as has been reported in many countries both in developing and developed economies [44].

Breastfeeding has been shown to be a simple, smart and cost effective measure that contributes immensely towards the realization of majority of the United Nations Sustainable Development Goals (SDG) by the year 2030, as sustenance of EBF could help to achieve the SDG targets of ending hunger, improving child nutrition, tackling obesity, ensuring healthy living and promotion of general wellbeing [32].

Hence to achieve these goals stronger breastfeeding policies and programmes are needed including further strengthening of baby friendly hospital initiative and baby friendly community initiative.

\section{Conclusions}

In conclusion, the EBF duration among respondents in the current study is low. 
Significant determinants were maternal education, maternal occupation, and gender of the child.

Improving girl child education, strengthening of baby friendly hospital initiative and adoption of baby friendly community initiative should be put in place to improve EBF rate and duration in our setting.

\section{Acknowledgements}

We wish to acknowledge all the mothers with their children who participated in this study.

\section{Conflicts of Interest}

None declared.

\section{Source of Funding}

None.

\section{References}

[1] UNICEF. Nutrition-Breastfeeding (2016). http://www.unicef.org/nutrition/index_24824.html

[2] Black, R.E., Victora, C.G., Walker, S.P., Bhutta, Z.A., Christian, P., de Onis, M., et al. (2013) Maternal and Child Undernutrition and Overweight in Low and Middle Income Countries. Lancet, 382, 427- 451. https://doi.org/10.1016/S0140-6736(13)60937-X

[3] World Health Organization (2009) Infant and Young Child Feeding (IYCF) Model Chapter for Textbooks for Medical Students and Allied Health Professionals. World Health Organization, Switzerland.

[4] Mihrshash, S., Oddy, W., Peat, J. and Kabir, I. (2008) Association between Infant Feeding Patterns and Diarrhoeal and respiratory Illnesses: A Cohort Study in Chittagong, Bangladesh. International Breastfeeding Journal, 3, 28. https://doi.org/10.1186/1746-4358-3-28

[5] James, D.C. and Lessen, R. (2009) Position of the American Dietetic Association Promoting and Supporting Breastfeeding. Journal of the American Dietetic Association, 109, 1926-1942. https://doi.org/10.1016/j.jada.2009.09.018

[6] Kio, J. (2015) Factors Influencing Breastfeeding Initiation and Contravention among Nursing Mothers in Nigeria: Evidence from Lagos State. IOSR Journal of Nursing and Health Sciences, 2, $01-07$.

[7] Booth, I. (2001) Does the Duration of Breastfeeding Matter? British Medical Journal, 322, 625- 626. https://doi.org/10.1136/bmj.322.7287.625

[8] Department of Health (2001) Infant Feeding Survey 2000: Statistical Press Release. HMSO, London. http://www.doh.gov.uk/public/infantfeedingaug01.pdf

[9] Earle, S. (2002) Factors Affecting the Initiation of Breastfeeding: Implications for Breastfeeding Promotions. Health Promotion International, 17, 205- 214. https://doi.org/10.1093/heapro/17.3.205

[10] Nigeria National Demographic and Health Survey, (2013) National Population Commission Federal Republic of Nigeria, Abuja, Nigeria 2014, 181-186. http://www.dhsprogram.com/pubs/pdf/FR/293/FR293 
[11] Ku, C. and Chow, S.K.Y. (2010) Factors Influencing the Practice of Exclusive Breastfeeding among Hong Kong Chinese Women: A Questionnaire Survey. Journal of Clinical Nursing, 19, 2434- 2445. https://doi.org/10.1111/j.1365-2702.2010.03302.x

[12] Nkala, T.E. and Msaya, S.E. (2011) Prevalence and Predictors of Exclusive Breastfeeding among Women in Kigoma Region, Western Tanzania: A Community Based Cross-Sectional Study. International Breastfeeding Journal, 6, 17. https://doi.org/10.1186/1746-4358-6-17

[13] Lawoyin, T.O., Olawuyi, J.F. and Onadeko, M.O. (2001) Factors Associated with Exclusive Breastfeeding in Ibadan, Nigeria. Journal of Human Lactation, 17, 321-325. https://doi.org/10.1177/089033440101700406

[14] Garret, R. and Ada, V. (1982) Infant Breastfeeding, Beliefs and Practices: A Study of Cameroonian Health Care Personnel. Journal of Tropical Pediatrics, 28, 209-215. https://doi.org/10.1093/tropej/28.4.209

[15] Kakute, P.N., Ngum, J., Nutchell, P., Kroll, K.A., Forgwei, G.W., Ngwang, L.K., et al. (2005) Cultural Barriers to Exclusive Breastfeeding by Mothers in a Rural Area of Cameroon, Africa. Journal of Midwifery \& Women's Health, 50, 324-328. https://doi.org/10.1016/j.jmwh.2005.01.005

[16] Cherop, C.E., Keverenge-Ettyang, A.G. and Mbagaya, G.M. (2009) Barriers to Exclusive Breastfeeding among Infants Aged 0-6 Months in Eldoret Municipality, Kenya. East African Journal of Public Health, 60, 69-72.

[17] Whaley, S.E., Meehan, K., Lange, L., Shusser, W. and Jenks, E. (2002) Predictors of Breastfeeding Duration for Employees of the Special Supplement Nutrition Program for Women, Infants, and Children (WIC). Journal of the American Dietetic Association, 102, 1290-1293. https://doi.org/10.1016/S0002-8223(02)90284-1

[18] Tan, K.L. (2011) Factors Associated with Exclusive Breastfeeding among Infant Under Six Months of Age in Peninsula Malaysia. International Breastfeeding Journal, 6, 2. http://www.internationalbreastfeedingjournal.com/contents/6/1/2 https://doi.org/10.1186/1746-4358-6-2

[19] Thurman, S.E. and Allen, P.J. (2008) Integrating Lactation Consultants into Primary Health Care Services: Are Lactation Consultants Affecting Breastfeeding Success? Paediatric Nursing, 34, 419-425.

[20] Oyedeji, G.A. (1985) Socio-Economic and Cultural Background of Hospitalized Children in Ilesha. Nigerian Journal of Paediatrics, 12, 111-117.

[21] Uchendu, U.O., Ikefuna, A.N. and Emodi, I.J. (2009) Factors Associated with Exclusive Breastfeeding among Mothers Seen at the University of Nigeria Teaching Hospital. South Africa Journal of Child Health, 3, 14-19.

[22] Mbada, C.E., Olowokere, A.E., Oyinlola-Aromolaran, F.C., Faremi, F.A., Ogundele, A.O., Awotidebe, T.C., et al. (2013) Knowledge, Attitude and Techniques of Breastfeeding among Nigerian Mothers from Semi-Urban Community. BMC Research Notes, 6, 552. https://doi.org/10.1186/1756-0500-6-552

[23] Oche, M.O. and Umar, A.S. (2008) Breastfeeding Practices of Mothers in a Rural Community of Sokoto, Nigeria. The Nigerian Postgraduate Medical Journal, 59, 789-796.

[24] Wojcicki, J.M., Gugig, R., Tran, C., Kathiravan, S., Holbrook, K. and Heyman, M.B. (2010) Early Exclusive Breastfeeding and Maternal Attitudes towards Infant Feeding in a Population of New Mothers in San Francisco, California. Breastfeeding Medicine, 5, 9-15. https://doi.org/10.1089/bfm.2009.0003 
[25] National Centre for Chronic Disease Prevention and Health Promotion; Division of Nutrition, Physical Activity and Obesity; Centre for Disease Control (2014) Breastfeeding Report Card, United States 2014. http://www.cdc.gov/breastfeeding/pdf/2014breastfeedingreportcard.pdf

[26] Sonko, A. and Worku, A. (2015) Prevalence and Predictors of Exclusive Breastfeeding for the First Six Month of Life among Women in Halaba Special Woreda, Southern Nations, Nationalities and People's Region/SNNPR/Ethiopia: A Community Based Cross-Sectional Study. Archives of Public Health, 73, 53. https://doi.org/10.1186/s13690-015-0098-4

[27] Vaderlinden, K. and Van de Putte, B. (2016) Pathways of Equality through Education: Impact of Gender (in)Equality and Maternal Education on Exclusive Breastfeeding among Native and Migrants in Belgium. Maternal \& Child Nutrition, 13. http://www.ncbi.nlm.nih.gov/pubmed/27169791

[28] Agho, K.E., Dibley, M.J., Odiase, J.I. and Ogbonmuku, S.M. (2011) Determinants of Exclusive Breastfeeding in Nigeria. BMC Pregnancy and Childbirth, 11, 2. http://www.biomed.central.com/1471-2393/11/2 https://doi.org/10.1186/1471-2393-11-2

[29] Oche, M.O., Umar, A.S. and Ahmed, H. (2011) Knowledge and Practice of Exclusive Breastfeeding in Kware, Nigeria. African Health Sciences, 11, 513-523.

[30] Dubois, L. and Girard, M. (2003) Social Determinants of Initiation, Duration and Exclusivity of Breastfeeding at the Population Level. The Results of Longitudinal Study of Child Development of Quebec CELDEQ 1998-2002. Canadian Journal of Public Health, 94, 300-305.

[31] Victora, C.G., Barros, A.J.D., Franca, G.V.A., Horton, S., Krasevec, J., Murch, S., Sankar, M.J. and Rollins, N.C. (2016) Breastfeeding in the $21^{\text {st }}$ Century: Epidemiology, Mechanics and Lifelong Effect. The Lancet, 387, 491-504. https://doi.org/10.1016/S0140-6736(15)01024-7

[32] Breastfeeding: A Key Sustainable Development. http://www.aliveandthrive.org/wp-content/uploads/2016/03/breastfeeding-and-SD Gs-20

[33] Katsinde, S.M. and Sinivas, S.C. (2016) Breastfeeding and the Sustainable Development Agenda. Indian Journal of Pharmacy Practice, 9, 144-146. https://doi.org/10.5530/ijopp.9.3.2

[34] Johnston, M.L. and Esposito, N. (2007) Barriers and Facilitators for Breastfeeding among Working Women in the United States. Journal of Obstetric, Gynaecologic and Neonatal Nursing, 36, 9-20. https://doi.org/10.1111/j.1552-6909.2006.00109.x

[35] Murtagh, L. and Moulton, A.D. (2011) Working Mothers, Breastfeeding, and the Law. American Journal of Public Health, 10, 217-223. https://doi.org/10.2105/AJPH.2009.185280

[36] Federal Government Extends Maternity Leave to 4 Months. http://www.bizwatchnigeria.ng

[37] United Nations Children Fund (UNICEF) and World Health Organization (WHO) (2015) World Breastfeeding Week Message. Breastfeeding and Work-Let's Make It Work. http://www.worldbreastfeedingweek.org

[38] Ayunbiade, O.M. and Ogunleye, O.V. (2012) Constraints to Exclusive Breastfeeding Practice among Breastfeeding Mothers in Southwest Nigeria: Implications for Sealing up. International Breastfeeding Journal, 7, 5.

http://www.itnernationalbreastfeedingjournal.com/content/7/1/5 https://doi.org/10.1186/1746-4358-7-5 
[39] Ahluwalia, I.B., Morrow, B. and Hsia, J. (2005) Why Do Women Stop Breastfeeding? Findings from the Pregnancy Risk Assessment Monitoring System. Paediatrics, 116, 1408-1412. https://doi.org/10.1542/peds.2005-0013

[40] Davies-Adetugbo, A.A. (1997) Socio-Cultural Factors and the Promotion of Exclusive Breastfeeding in Rural Yoruba Communities of Osun State. Social Science \& Medicine, 45, 113-125. https://doi.org/10.1016/S0277-9536(96)00320-6

[41] Lewallen, L.P., Dick, M.J., Flowers, J., Powell, W., Zickefoose, K.T. and Wall, Y.G. (2006) Breastfeeding Support and Early Cessation. Journal of Obstetrics, Gynaecologic and Neonatal Nursing, 35, 116-172. https://doi.org/10.1111/j.1552-6909.2006.00031.x

[42] Sacco, L.M., Caulifield, L.E., Gittelsohn, J. and Martinez, H. (2006) The Conceptualization of Perceived Insufficient Milk among Mexican Mothers. Journal of Human Lactation, 22, 271-286. https://doi.org/10.1177/0890334406287817

[43] WHO Evidence for the Ten Steps to Successful Breastfeeding. https://www.int/nutrition/bfhi/ten-steps/en

[44] Ekanem, E.E. and Fajola, A.O. (2016) Need for Baby Friendly Community Initiative to Improve the Low Exclusive Breastfeeding Rates in Nigeria. Nigerian Journal of Paediatrics, 43, 229-230. https://doi.org/10.4314/njp.v43i3.13

[45] World Health Organization (WHO) (2002) Infant and Young Child Nutrition. 55th World Health Assembly, Geneva, 13-18 May 2002, 1-3.

http://apps.who.int/gb/archive/pdf_files/WHA55/ewha5525.pdf 